Supplement of Hydrol. Earth Syst. Sci., 21, 3145-3165, 2017

https://doi.org/10.5194/hess-21-3145-2017-supplement

(c) Author(s) 2017. This work is distributed under

the Creative Commons Attribution 3.0 License.

(c) (1)

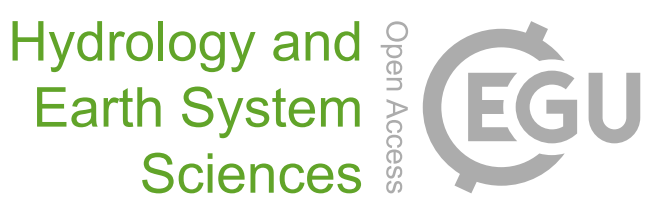

Supplement of

\title{
Modeling the water budget of the Upper Blue Nile basin using the JGrass-NewAge model system and satellite data
}

Wuletawu Abera et al.

Correspondence to: Wuletawu Abera (wuletawu979@gmail.com) and Riccardo Rigon (riccardo.rigon@ing.unitn.it)

The copyright of individual parts of the supplement might differ from the CC BY 3.0 License. 


\section{Precipitation maps of UBN basin}

The spatial and temporal variability of $\mathrm{J}(\mathrm{t})$ is analyzed in this section. The spatial distribution of long term mean daily and annual precipitation is presented in figure $1 \mathrm{a}$ and $\mathrm{b}$. SM2R-CCI shows that south and southwest part of the basin receives high precipitation while the east and northeast part of the highland receives low precipitation. Along the long term annual mean, the long term daily mean is reported.
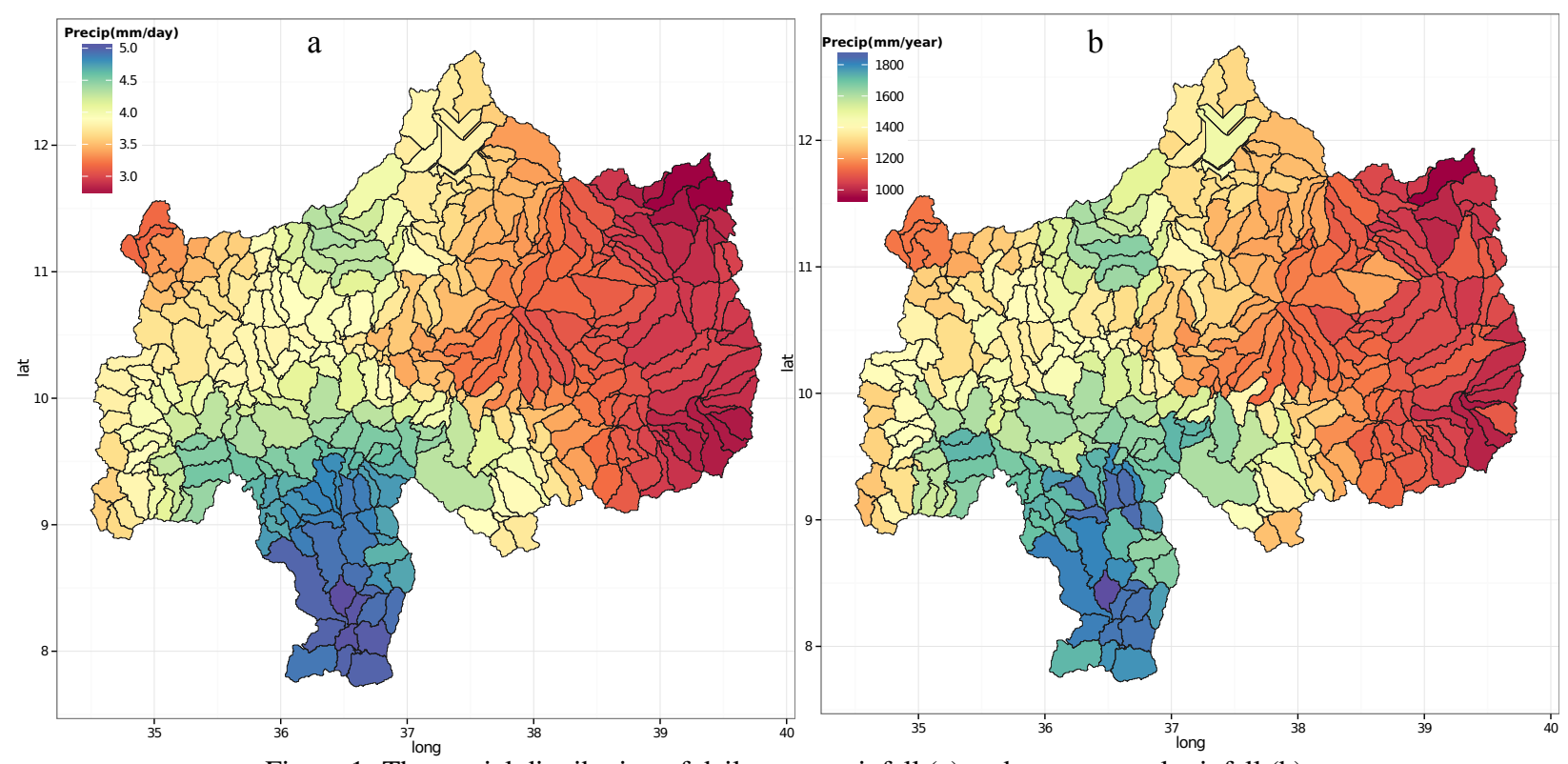

Figure 1: The spatial distribution of daily mean rainfall (a) and mean annual rainfall (b),

\section{NewAge and MODIS Evapotranspiration estimation comparison}

Figure 2 shows a sample of spatial and temporal estimation of MOD16 and NewAge ET for some systematically selected (selected from the four seasons) at 8-days time resolution. While the spatial pattern has some similarities, the magnitudes of ET amount between the model and MOD16 estimation is different. In all the maps, ET tends to be high in the lowlands of the basin (western part). MOD16 estimation, however, considerable underestimates ET in comparison to NewAge. Time series comparison of two ET from 2000-2009 for some selected subbasin (figure 3 ) shows that MOD16 highly underestimates ET. Other studies also show similar results that MOD16 considerably underestimate in comparison to some model estimations and eddy covariance flux towers data (Yilmaz et al., 2014. Knipper et al., 2016, Schaffrath and Bernhofer, 2013; Ramoelo et al., 2014).

NewAge revealed high level of temporal variability while MOD16 shows similar temporal patterns between the years. The agreement between the two estimations vary from subbasin to subbasin (figure 3). For instance, in figure $3 \mathrm{p}$ shows relatively better consistency while figure $3 \mathrm{~d}$ has lower agreement between the two. The spatial distribution of the correlation and PBIAS between the model and MOD16 data is presented in figure 4 $\mathrm{a}$ and $\mathrm{b}$ respectively. The NewAge estimation in the eastern part of the basin shows higher correlation with the MOD16 data, while the correlation tends to decrease systematically towards the west i.e. to the lowlands (figure 4 a). Similarly, the PBIAS shows that the western part, border to the Sudan, has very high underestimation (figure $4 \mathrm{p}$ ). The overall correlation and PBIAS between NewAge and MOD16 is $0.48 \pm 0.15$ and $14.5 \pm 18.9$ respectively. Based on the consistency we made, and our ability to characterize the other water budget solution with observation and GRACE, we can point out that the performance of MOD16 is low, and need to be improved in this region. 


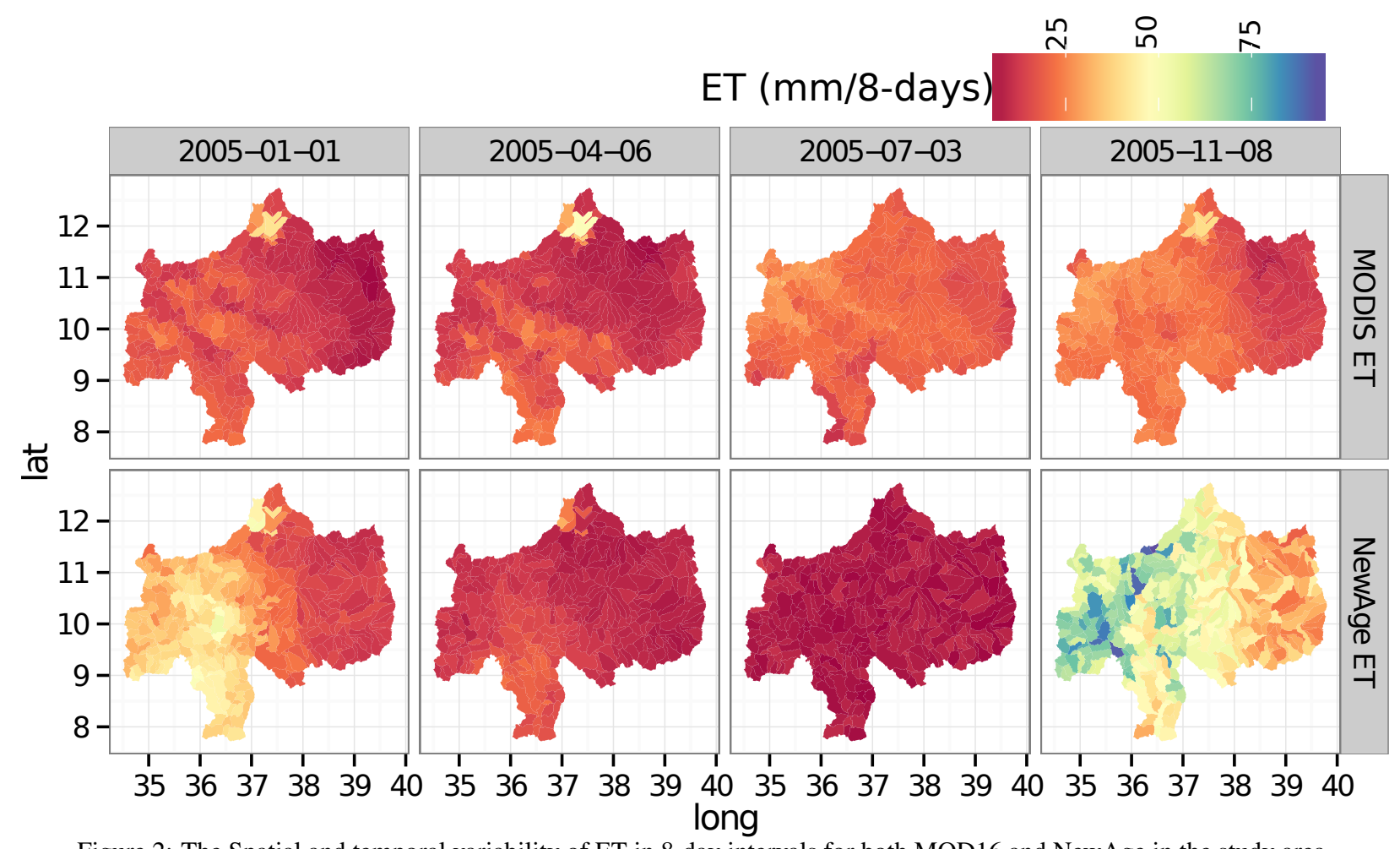

Figure 2: The Spatial and temporal variability of ET in 8-day intervals for both MOD16 and NewAge in the study area. 


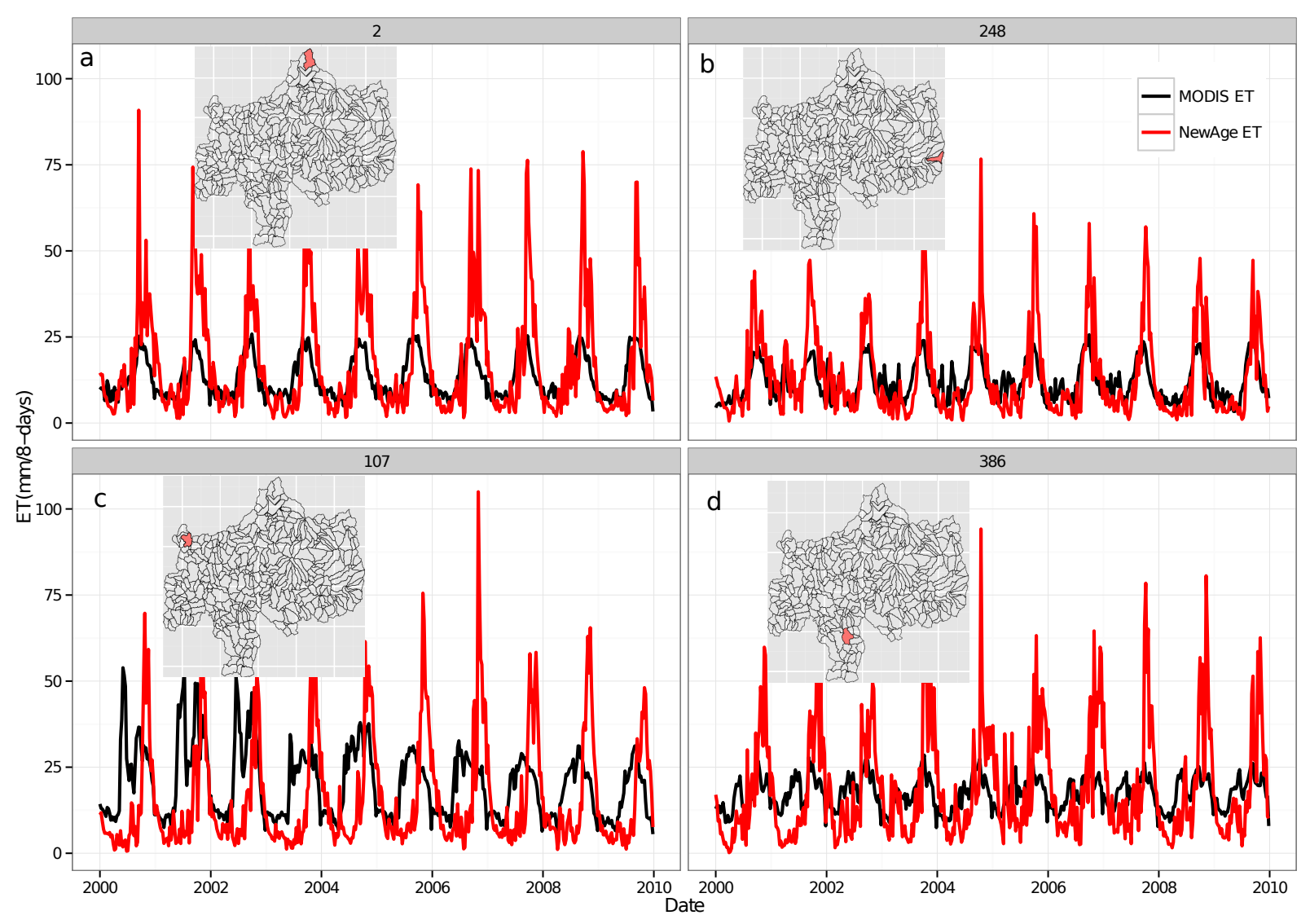

Figure 3: Time series ET estimation with NewAge and MOD16 at 8-days of time steps for four subbasin: subbasin ID2 (a), subbasin ID248 (b), subbasin ID107 (c) and subbasin ID386 (d). The location of the subbasin are indicated in the map inside the plots. 


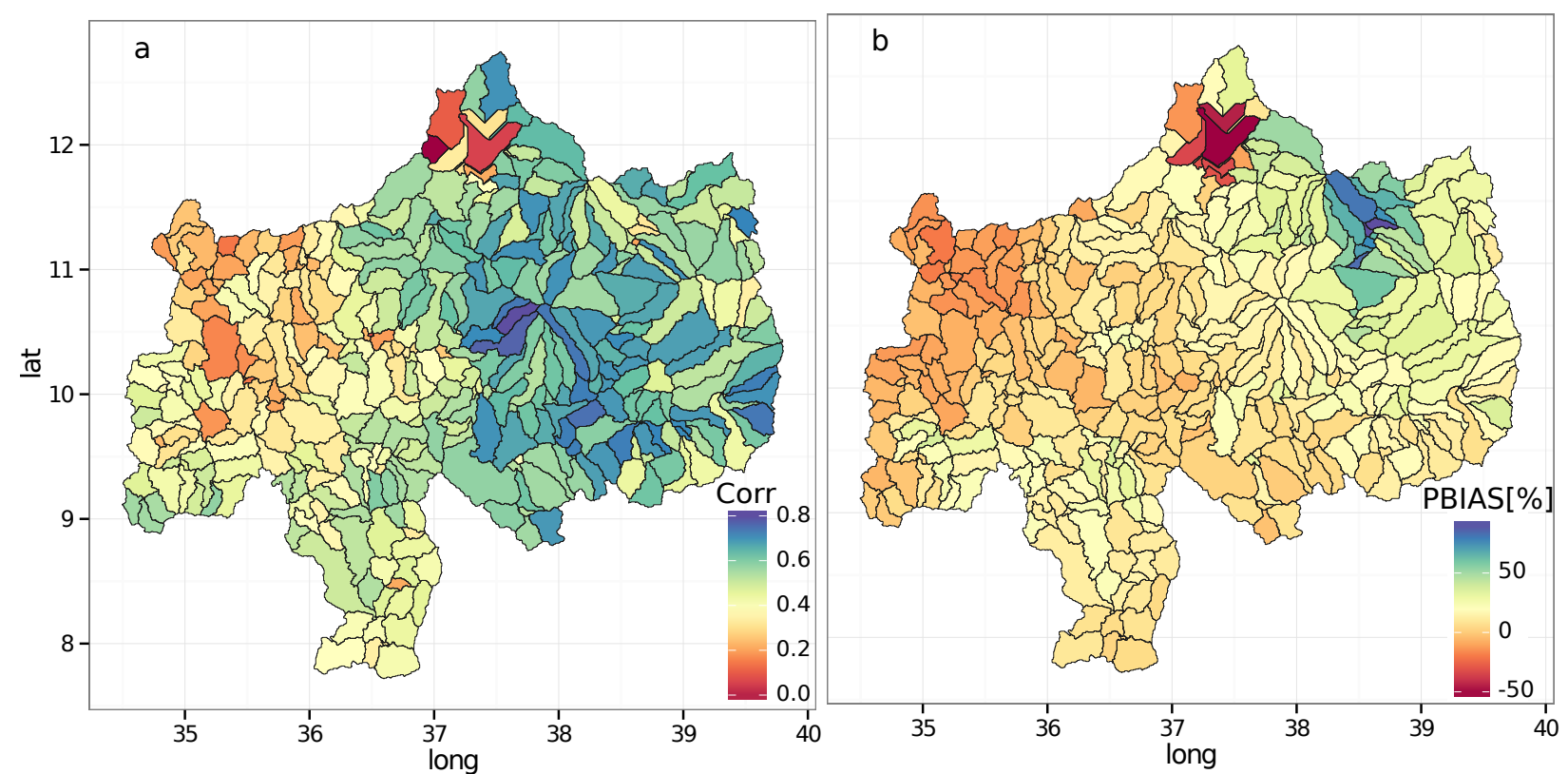

Figure 4: The spatial distribution of correlation Coefficient (a) and PBIAS between NewAge and MOD16 ET estimations at 8-days time steps. 


\section{NewAge simulation at each link}

A sample of spatially distributed daily discharge at all the channel links is shown in figure ??. Here, the daily discharge for the first day of May, June, July, August, September and October are presented to show the spatiotemporal dynamics of discharge.

\section{NewAge and GRACE storage change maps}

The spatial distribution of NewAge $d s / d t$ and GRACE based TWSC for four months (January, April, July, and October) of 2005 is shown at figure 5. The comparison is based on the NewAge modelling at subbasin scale, and GRACE grid resolution of $1^{0}$. Due to the possible high leakage error introduced at high spatial resolution (Swenson and Wahr 2006), statistical comparison at subbasin level is not performed. However, focusing on maps of the sample months, some level of similar spatial and temporal pattern is revealed (figure 5).

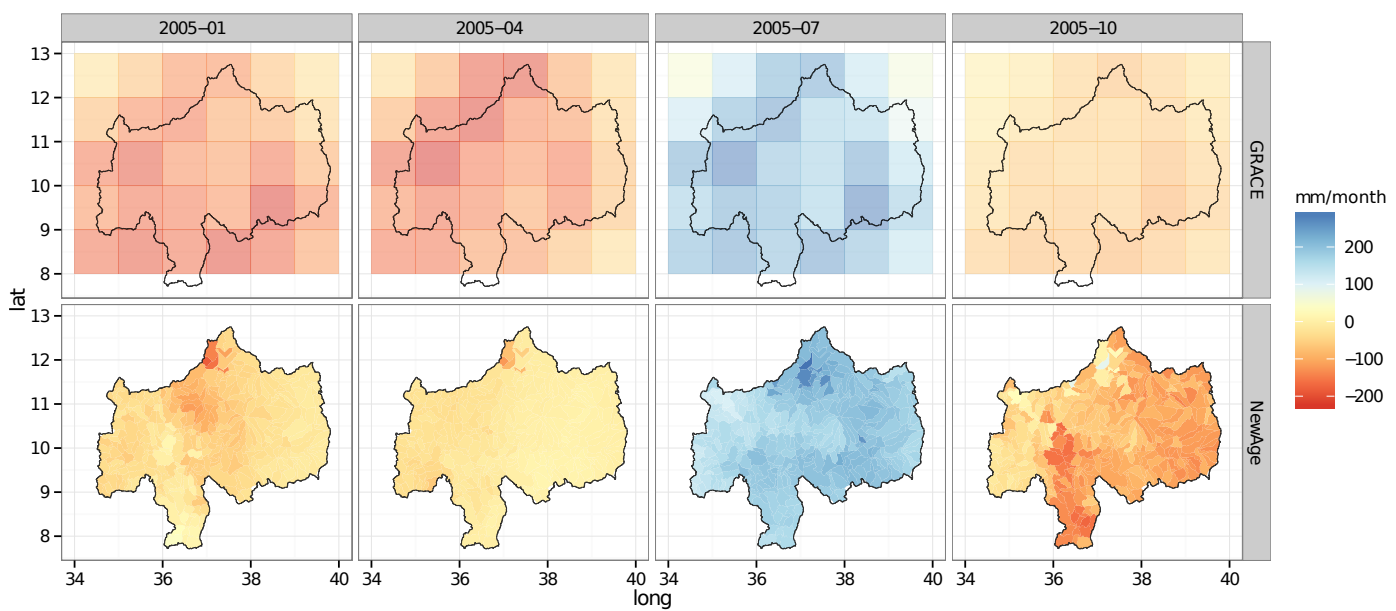

Figure 5: Comparison of Spatial distribution of NewAge $d s / d t$ and GRACE TWSC for January, April, July, and October 2005. Note that the sptial resolution of NewAge $d s / d t$ and GRACE is subbasin scale and $1^{0} \mathrm{X} 1^{0}$ respectively

\section{References}

Knipper, K. R., Kinoshita, A. M., Hogue, T. S., 2016. Evaluation of a moderate resolution imaging spectroradiometer triangle-based algorithm for evapotranspiration estimates in subalpine regions. Journal of Applied Remote Sensing 10 (1), 016002-016002.

Ramoelo, A., Majozi, N., Mathieu, R., Jovanovic, N., Nickless, A., Dzikiti, S., 2014. Validation of global evapotranspiration product (mod16) using flux tower data in the african savanna, south africa. Remote Sensing 6 (8), 7406-7423.

Schaffrath, D., Bernhofer, C., 2013. Variability and distribution of spatial evapotranspiration in semi arid inner mongolian grasslands from 2002 to 2011. SpringerPlus 2 (1), 547.

Swenson, S., Wahr, J., 2006. Post-processing removal of correlated errors in grace data. Geophysical Research Letters 33 (8).

Yilmaz, M. T., Anderson, M. C., Zaitchik, B., Hain, C. R., Crow, W. T., Ozdogan, M., Chun, J. A., Evans, J., 2014. Comparison of prognostic and diagnostic surface flux modeling approaches over the nile river basin. Water Resources Research 50 (1), 386-408. 